\title{
Emotional Violence in selected Ian McEwan's Fiction
}

\author{
Mina Abbasiyannejad and Faride Pourgiv \\ Department of Foreign Languages and Linguistics, Faculty of Literature and Humanities, \\ Shiraz University, Shiraz, Iran
}

\begin{abstract}
Violence has always been a controversial and much debated topic in English fiction. Various authors such as Ian McEwan have presented different aspects of violence in their fiction, with men typically treating women as inferior and emotionally violating them. Emotional violence is a significant type of violence although less acknowledged; It erodes and eventually destroys intimate relationships and cruelly continues due to denial, lack of victim's knowledge, and shame. This paper aims to show how emotional violence is presented through stereotyped gender roles. It is argued that the socio-cultural norms in patriarchal society permit men to emotionally trample on the rights of women and children, by virtue of their perceived superior roles.
\end{abstract}

Keywords: McEwan, emotional violence, gender, socio-cultural, contemporary fiction

\section{Introduction}

Contemporary fiction deals with a wide range of violence such as physical, emotional, sexual, and verbal among others. All of the mentioned types of violence are interlinked, and all culminate in the emotional violation of the victim. Ian McEwan as a prominent contemporary author shifts from dark issues in his early works to more socio-cultural themes and/as according to Groes (2009), his novels "contain many of the themes and obsessions that he continues to explore, in a more subtle and refined way" [1]. McEwan's interest in delving into intimate relationships is not hidden from anyone, and along the same lines, Clark, and Gorden (2003) comment that McEwan explores "personal levels of human experience" [2].

Emotional violence that basically occurs between intimate partners is considered a personal experience that McEwan profoundly demonstrates in his fiction to shed light on the invisible causes behind dysfunctional relationships. His work illuminates how emotional violence could result in trauma, and finally unsatisfactory relationships. In contemporary fiction all kinds of violence are presented in various ways, subtly or in their full brutal reality. As examples, The Cement Garden, and Atonement portray emotional violence in a complicated but structured way. Some examples of emotional abuse are discussed in this paper such as discounting and negating, blaming and "silent treatment" and judging in order to manipulate. In fact, many dysfunctional relationships are the results of emotional violence and end in separation and divorce. This paper aims to identify and discuss examples of emotional violence that are manifested through unequal gender roles in selected McEwan's novels.

\section{What is Emotional Violence?}

Emotional violence is defined by Engel (2002) as "any nonphysical behavior that is designed to control, intimidate, subjugate, demean, punish, or isolate another person through the use of degradation, humiliation, or fear" [3]. Emotional violence is mostly considered as a type of violence which causes severe and irreparable damage or harm [4]. In fact, emotional violence has many dimensions and understanding them would help in dealing with them in order to predict the consequences. Emotional violence can be devastating since it basically 
comes from the people that you know and love such as parents, and spouses. Being treated wrongly and harshly by people from whom you expect love and comfort can leave lifelong scars ( [5].

Several damaging effects of emotional abuse are such as "depression, lack of motivation, confusion, difficulty concentrating or making decisions, low self-esteem, feelings of failure or worthlessness, feelings of hopelessness, self-blame, and self-destructiveness" [3]. Despite its significance, emotional abuse is neglected due to three important attitudes. Firstly it has less immediate or lower risk of physical injury; secondly it is invisible to others and finally and most importantly, it occurs much more frequently than other types of violence, and becomes a normal part of the intimate relationship rather than being considered as a social problem [6].

Emotional violence is not limited to negative behaviors; negative attitudes are also important as well. This means that emotional violence does not necessarily occur in an obvious and "overt action," but shown in such ways as listed below:

- "Believing that others should do as you say.

- Not noticing how others feel.

- Not caring how others feel.

- Believing that everyone else is inferior to you.

- Believing that you are always right" [3].

Emotional or psychological abuse, as it is sometimes called, covers a wide range of abusive behaviors that consist of attempting to hurt or damage the victim's self-esteem by "degrading and belittling" behaviors. Other effective actions that could be considered as emotional violence include "Name-calling, ridiculing, blaming, swearing at, criticizing, and jealousy among a wide range of tactics that can be used to gain power and control over another individual" [6]. While physical violence is always highlighted by people and institutions, some studies have shown that the impact of emotional or psychological violence in general is much more severe and has everlasting effects and consequences on the victims [7].

While women are typically the most emotionally abused they rarely end the relationship and decide to continue to stay in an unhealthy relationship bearing with the outcomes that appear in the form of sickness such as chronic headaches. However, the problem is bigger than it looks and disregarding economic necessity which forces the women to continue the unhealthy relationship Barnett and LaViolette (1993) conclude that the victim must choose to stay in a relationship or face the cultural system that "devalues women, especially unmarried women" and put the burden and responsibility squarely on the women's shoulders because they will be blamed as being responsible for the failed relationships [8].

\section{Discussion}

Contemporary fiction presents violence, in general and emotional violence, in particular. It seeks the causes of dysfunctional relationships in emotional violence as a very important factor that significantly deteriorates love and replaces it with loath and hatred instead. Examples of such kinds of emotional violence can be found in the Atonement and The Cement Garden as contemporary fiction.

Atonement (2001) is a much praised work which expresses a new and powerful sense of history with an appreciation for the patterns of individual lives and actions within the tide of great events, in this case the 193945 war. Hidalgo (2005), sees Atonement that as a novel with "multilayered texture" [9]. Atonement (AT) is the story of failure of relationship between Jack Tallis and his wife, Emily. The emotional violence is shown in a profound way to highlight the domineering attitude of gender roles. Although there is no legal divorce or total separation, they do not live together practically, while there are implications of Jack's infidelity that Emily is aware of, "That he worked late she did not doubt, but she knew he did not sleep at his club, and he knew that she knew this. But there was nothing to say. Or rather there was too much" [10]. What yields itself to debate here is that Emily is aware of her husband's deceit but accepts and remains as a wife without objection. Engel (2002) describes the effect of betrayal on love relationship as such: "love feelings can be destroyed by feelings of anger 
when our hopes are dashed, or when we come to feel rejected, betrayed, or abandoned by our partner" [3]. The patriarchal system in fact reassures Jack to act as he wishes and according to Evans (2011) "that the system discriminated against the poor and women. Men but not women could sue for divorce on the grounds of adultery [11].

Similarly The Cement Garden (CG) presents a man with domineering attitudes who emotionally abuses his family, in a quite subtle way. The male character is ignorant and withholds love and affection, and judges the family members unfairly. The father ignores the mother's explanation, ridiculing her, and making jokes of her weak points. While the mother tries to convince the father to return the cement the father uses "(a) penknife to scrape black shards from the bowl of his pipe... He knows how to use his pipe against her" [12]. His attempts at ignorance are shown by the act of replacing the "pipe between his teeth like a missing section of his own anatomy and interrupted to say it was 'out of the question' sending the bags back and that was the end of it [12]. While he is busy cleaning his pipe and without consideration and blatantly throws what he is cleaning on the food that his wife has cooked, cold bloodedly and impolitely refuses her request by only saying that it is "out of the question" which leaves no place for more conversation, and that was the end. Her voice was "choked with exasperation" [12]. She did not continue the conversation knowing how useless it would be. The mother is emotionally distanced from her husband since she is constantly violated by him, through his belittling and degrading behavior.

In both Atonement and The Cement Garden, the female characters remain in the respective abusive relationships without having any objections, which begs the question why. The shame and discomfort of divorce is so effective that they prefer to continue abusive relationships. Although after World War II divorce rates increased significantly, it was considered an unacceptable act in society, and "its occurrence was rare until 1950" [13].

\section{Conclusion}

Emotional violence has been always one of the most serious concerns of intimate relationships. Despite its importance it is usually denied or overlooked by the victims. Compared to other forms of violence, emotional violence is more subtle and complicated since it is not observable and sometimes neither abuser nor abused realizes its occurrence. It is manifested in fiction and shows its devastating effects on a couple's relationship. It is shown in the form of betrayal, ignorance, withholding love and affection, etc. Female characters in the selected stories undergo emotional violence at different levels while male characters act arrogantly as superiors while ignoring and humiliating their female partners, and causing them constant emotional trauma throughout their lives which affects the depth of their love relationships. In fact victims may even not recognize that they are being abused and maltreated or they probably have lost their self-esteem to oppose, object, and defend their right. What emotional violence does to its victims is to make them believe that they are worthless and unable to do anything good enough, so they remain silent, and the perpetrator continues to control them. Employing gestures that convey humiliations, as shown in The Cement Garden is an intentional attempt of ignorance and belittling of the wife in a systematic way. In the case of Atonement, the wife is emotionally disturbed by the knowledge of her husband's betrayal.

\section{Acknowledgments}

The authors wish to acknowledge and thank the support of Department of Foreign Languages and Linguistics, Faculty of Literature and Humanities of Shiraz University. 


\section{References}

[1] Groes, S. Ian McEwan: Contemporary Critical Perspectives. New York: Continuum Intl Pub Group, 2009, p.7.

[2] Clark, R, and Gordon, A. Ian McEwan's Enduring Love: A Reader's Guide. United States of America: Continuum Intl Pub Group, 2003., p7.

[3] Engel, B. The emotionally abusive relationship: How to stop being abused and how to stop abusing. New Jersey: John Wiley \& Sons, 2002, p.10-11, p 12, p.41.

[4] Fischer, K. L., \& McGrane, M. (1997). Journey Beyond Abuse: A Step-by-Step Guide to Facilitating Women's Domestic Abuse Groups. Amherst H. Wilder Foundation, 1997.

[5] Copeland, M. E., \& Harris, M. Healing the trauma of abuse: A women's workbook. Oakland, CA: New Harbinger Publication, 2000, p.15.

[6] Gelles, R.F. Intimate violence and abuse in families.4th edition. New York: Oxford press, 2017, p.80, p.16.

[7] Loseke, D. R., \& Kurz, D. Men's violence toward women is the serious social problem. In. D. Loseke, R. J. Gelles, \& M. C. Cavanaugh, Eds., Current Controversies on Family Violence (2nd ed., pp. 79- 96). Thousand Oaks, CA: Sage Publications, 2005.

[8] Barnett, O. W., \& LaViolette, A. D. (1993). It Could Happen to Anyone: Why Battered Women Stay. Newbury Park, CA: Sage Publications, 1993.

[9] Hidalgo, P. "Memory and Storytelling in Ian McEwan's Atonement." Critique: Studies in Contemporary Fiction , 46.2 82-91, 2005, p.83.

[10] McEwan, I. Atonement. New York: Vintage, 2001, p.139.

[11]Evans, T. " The Other Woman and Her Child: Extra Marital Affairs and Illegitimacy in Twentieth Century Britain." Women's History Review, 20.1 47-65, 2011, p.48-49.

[12] McEwan, I. The Cement Garden. Baltimore: Anchor, 1978, p.3-4.

[13] Emery, R. E. (Ed.). Cultural sociology of divorce: An encyclopedia. Los Angeles: Sage Publications, 2013, p.89. 